\title{
A CD28 superagonistic antibody elicits 2 functionally distinct waves of $T$ cell activation in rats
}

\author{
Nora Müller, ${ }^{1}$ Jens van den Brandt, ${ }^{2}$ Francesca Odoardi, 3,4 Denise Tischner, ${ }^{2}$ Judith Herath, ${ }^{2}$ \\ Alexander Flügel,,$^{3,4}$ and Holger M. Reichardt'1,2

\begin{abstract}
${ }^{1}$ Institute for Virology and Immunobiology, University of Wuerzburg, Wuerzburg, Germany. ${ }^{2}$ Department of Cellular and Molecular Immunology, University of Goettingen Medical School, Goettingen, Germany. 3Department of Neuroimmunology, Max Planck Institute of Neurobiology,
\end{abstract} \\ Martinsried, Germany. ${ }^{4}$ Institute for Immunology, Ludwig Maximilians University Munich, Munich, Germany.
}

\begin{abstract}
Administration of the CD28 superagonistic antibody JJ316 is an efficient means to treat autoimmune diseases in rats, but the humanized antibody TGN1412 caused devastating side effects in healthy volunteers during a clinical trial. Here we show that JJ316 treatment of rats induced a dramatic redistribution of Tymphocytes from the periphery to the secondary lymphoid organs, resulting in severe $\mathrm{T}$ lymphopenia. Live imaging of secondary lymphoid organs revealed that JJ316 administration almost instantaneously ( $<2$ minutes) arrested T cells in situ. This reduction in $\mathrm{T}$ cell motility was accompanied by profound cytoskeletal rearrangements and increased cell size. In addition, surface expression of lymphocyte function-associated antigen-1 was enhanced, endothelial differentiation sphingolipid $\mathrm{G}$ protein-coupled receptor 1 and $\mathrm{L}$ selectin levels were downregulated, and the cells lost their responsiveness to sphingosine 1-phosphate-directed migration. These proadhesive alterations were accompanied by signs of strong activation, including upregulation of CD25, CD69, CD134, and proinflammatory mediators. However, this did not lead to a cytokine storm similar to the clinical trial. While most of the early changes disappeared within 48 hours, we observed that $\mathrm{CD}^{+} \mathrm{CD}^{+} 5^{+} \mathrm{FoxP}^{+}$regulatory $\mathrm{T}$ cells experienced a second phase of activation, which resulted in massive cell enlargement, extensive polarization, and increased motility. These data suggest that CD28 superagonists elicit 2 qualitatively distinct waves of activation.
\end{abstract}

\section{Introduction}

Efficient activation of naive $T$ cells by antigen-presenting cells requires the concomitant engagement of the TCR and the costimulatory molecule CD28 (1). These 2 signals result in an upregulation of cell-surface receptors such as CD25 (IL-2R $\alpha$ ), CD69, CD134 (Ox40), and lymphocyte function-associated antigen-1 (LFA-1) $\left(\alpha_{L} \beta_{2}\right.$ integrin), diminished levels of the sphingosine 1-phosphate $(\mathrm{S} 1 \mathrm{P})$ receptor endothelial differentiation sphingolipid G protein-coupled receptor 1 (EDG-1) and CD62L (L selectin), synthesis of effector cytokines and chemokines, a dynamic rearrangement of the F-actin cytoskeleton, and finally, clonal expansion of the activated $T$ cell population (2-6). In contrast to classical costimulation, CD28 superagonistic antibodies, such as JJ316 in the rat and TGN1412 in humans, allow for the activation and expansion of T cells without the need of TCR engagement (7). Previous studies indicated that these antibodies preferentially address $\mathrm{CD}^{+}{ }^{+} \mathrm{CD} 25^{+} \mathrm{FoxP}^{+}$Tregs (8), a lymphocyte subpopulation that arises in the thymus and can be distinguished from other $\mathrm{CD}^{+}$ $T$ cells by their distinct expression pattern and the ability to suppress lymphocyte proliferation (9). Notably, the expansion of bona fide Tregs by CD28 superagonistic antibodies has been proposed to underlie the beneficial effects of these drugs in the treatment of autoimmune diseases such as EAE in rats $(10,11)$. While the effi-

Nonstandard abbreviations used: EDG-1, endothelial differentiation sphingolipid G protein-coupled receptor 1; LFA-1, lymphocyte function-associated antigen-1; $\mathrm{MBP}$, myelin basic protein; SEM, scanning electron microscopy; S1P, sphingosine 1-phosphate.

Conflict of interest: The authors have declared that no conflict of interest exists. Citation for this article: J. Clin. Invest. 118:1405-1416 (2008). doi:10.1172/JCI32698. cacy in animal models is undoubted, administration of the humanized CD28 superagonistic antibody TGN1412 to healthy volunteers caused devastating side effects (12). Within a few hours, a single i.v. dose induced severe lymphopenia and a systemic inflammatory response leading to multiorgan failure. Recent data suggest that the massive cytokine release encountered after TGN1412 administration might be a specific feature of human immune cells (13). However, whether such species differences also apply to the other adverse effects of TGN1412 remains elusive. Stimulated by the apparent discrepancy between the beneficial effects observed in animals and the outcome of the recent clinical trial in humans, we reinvestigated the properties of the $\mathrm{CD} 28$ superagonistic antibody JJ316 in rats. Our results demonstrate that the effects of JJ316 follow a biphasic course. Almost instantaneously after i.v. infusion, $T$ cells are arrested within the secondary lymphoid organs and form clusters. This leads to a dramatic redistribution from the periphery to the spleen and lymph nodes, resulting in severe $\mathrm{T}$ lymphopenia similar to the clinical trial in humans. The trapped $\mathrm{T}$ cells become strongly activated, as indicated by cytoskeletal rearrangements, an altered density of cell surface receptors, and increased mRNA expression of proinflammatory cytokines and chemokines. Contrasting to the scenario in humans, however, cytokine serum levels remain moderate. These immediate changes are later followed by a second qualitatively different phase of activation that mainly pertains bona fide Tregs. Thus, CD28 superagonistic antibodies elicit 2 distinct waves of $\mathrm{T}$ cell activation.

\section{Results}

JJ316 causes profound T lymphopenia by inducing redistribution of T cells to the secondary lymphoid organs. To analyze the effects of JJ316 on 

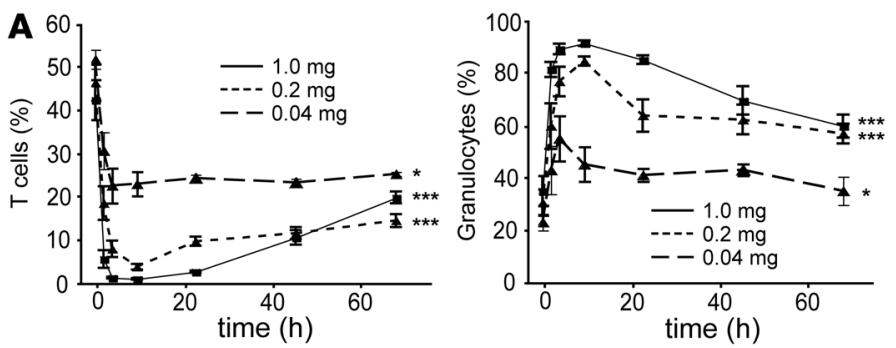

B
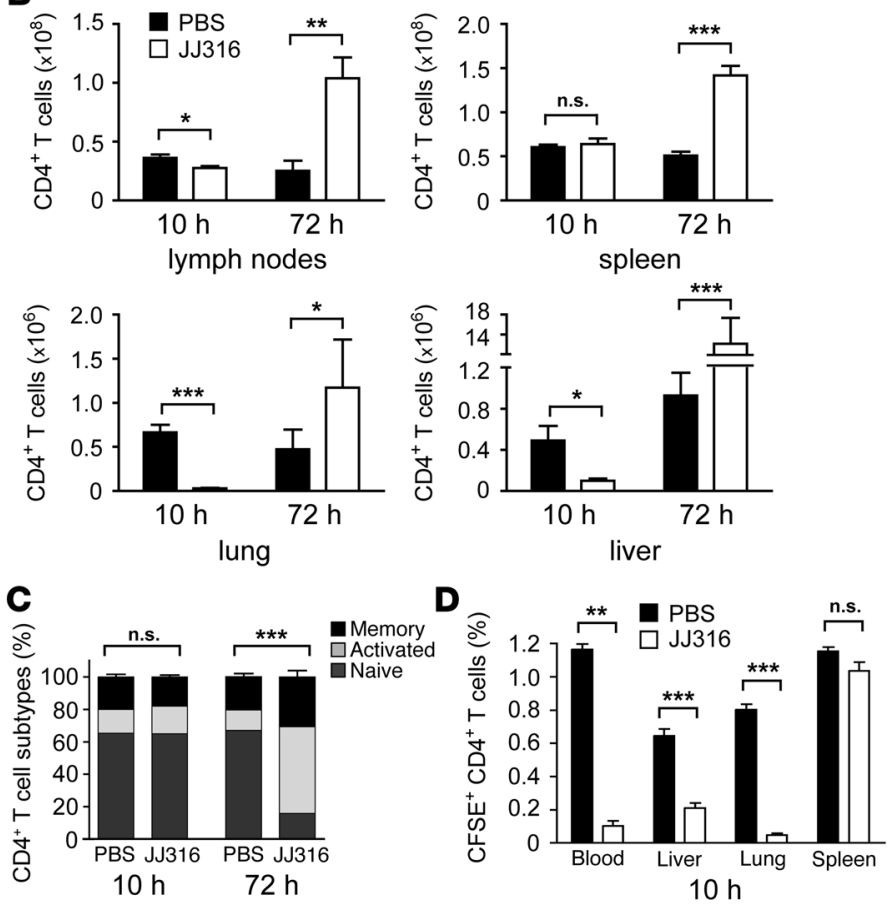

\section{Figure 1}

Administration of JJ316 induces T lymphopenia and leads to the redistribution of $\mathrm{CD}^{+}{ }^{+} \mathrm{T}$ cells. (A) Blood samples from rats i.v. injected with $1.0 \mathrm{mg}, 0.2 \mathrm{mg}$, or $0.04 \mathrm{mg} \mathrm{JJ} 316$ were taken at the indicated time points and analyzed for the percentages of circulating $T$ cells (left panel) and granulocytes (right panel) by flow cytometry. $n=6$; mean \pm standard error of the mean. Statistical analysis refers to the individual comparison of each time course to untreated control rats by 1 -way ANOVA. (B) Leukocytes were isolated from lymph nodes, spleen, lung, and liver 10 and 72 hours after injection of $1.0 \mathrm{mg}$ JJ316 or PBS as a control. Subsequently, the total number CD4+ $\mathrm{T}$ cells was determined by microscopic counting followed by flow cytometric analysis of CD4 and TCR $\beta$ expression. $n=3$; mean \pm standard error of the mean. (C) The relative frequencies of $C D 4^{+}$naive $\left(C D 45 R C+R T 6.1^{+}\right)$, activated (CD45RC-RT6.1-), and memory T cells (CD45RC-RT6.1+/ CD45RC+RT6.1-) was determined 10 and 72 hours after application of JJ316 or PBS. Thy-1+ RTEs (recent thymic emigrants) were excluded from the analysis. $n=3$; mean \pm standard error of the mean. (D) CFSE-labeled lymphocytes $\left(4 \times 10^{7}\right)$ were transferred into recipient rats i.v., and 3 days later $0.2 \mathrm{mg} J J 316$ or PBS were administered. After 10 hours the frequencies of $\mathrm{CFSE}^{+} \mathrm{CD}^{+}$ T cells in blood, liver, lung, and spleen were determined by microscopic counting and flow cytometry. $n=3$; mean \pm standard error of the mean. ${ }^{*} P<0.05 ;{ }^{* *} P<0.01 ;{ }^{* * *} P<0.001$. lymphocyte homing behavior we injected $1 \mathrm{mg}, 0.2 \mathrm{mg}$, and 0.04 $\mathrm{mg}$ of the CD28 superagonistic antibody and determined the relative frequencies of the major leukocyte subpopulations in blood over a 72-hour period. At the highest antibody dose, $T$ cell counts dropped from around $40 \%$ to almost undetectable levels within 4 hours (Figure 1A). Concomitantly, the frequency of B cells was mildly diminished and the percentage of granulocytes strongly increased (Figure 1A and data not shown). The severe T lymphopenia persisted for 24 hours and then slowly returned towards original levels (Figure 1A). The impact of JJ316 was dose dependent, but even at a concentration of $0.04 \mathrm{mg}$ the antibody was still significantly effective (Figure 1A).

Subsequently, we determined absolute numbers of lymphocyte subpopulations in spleen, lymph nodes, lung, and liver. The abundance of CD4 ${ }^{+} \mathrm{T}$ cells in the secondary lymphoid organs was essentially unaltered 10 hours after injection of the CD28 superagonistic antibody, i.e., at a time when $\mathrm{T}$ lymphocytes became virtually undetectable in peripheral blood (Figure 1B). In contrast, CD4 ${ }^{+}$ $\mathrm{T}$ cell counts in lung and liver were significantly diminished by $95 \%$ and $80 \%$, respectively (Figure 1B). Importantly, the number of B cells did not change in any of those organs (data not shown). Apparently, the JJ316-induced T lymphopenia is not a consequence of a redistribution of cells into extralymphoid organs, but instead, $\mathrm{T}$ cells rather seem to be selectively retained in the lymph nodes and spleen. In compliance, JJ316 did not induce a memory pheno- type in $\mathrm{CD}^{+} \mathrm{T}$ cells based on the classification by O'Sullivan et al. $(14,15)$. Flow cytometric analysis, using antibodies against Thy-1, CD45RC, and RT6.1, revealed unaltered frequencies of naive, activated, and memory $T$ cells in the lymph nodes after 10 hours, suggesting that CD28 superagonistic antibodies do not fundamentally impact $\mathrm{T}$ cell identity (Figure 1C).

It was previously reported that infusion of JJ316 induces a proliferative response of T cells at later time points (11). Accordingly, we observed strongly increased numbers of $\mathrm{CD}^{+} \mathrm{T}$ cells 72 hours after JJ316 application in all organs analyzed (Figure 1B). Concomitantly, the relative frequencies of activated and memory $\mathrm{T}$ cells were increased, suggesting that the proliferative response preferentially pertains to mature $\mathrm{T}$ cell populations (Figure 1C).

To confirm trapping of $\mathrm{T}$ cells in the secondary lymphoid organs, we adoptively transferred CFSE-labeled lymphocytes to wild-type rats and studied their redistribution after JJ316 injection. Within 10 hours, the frequency of the $\mathrm{CFSE}^{+} \mathrm{CD}^{+} \mathrm{T}$ cells was profoundly reduced in blood, liver, and lung while their cellularity in spleen remained unaltered (Figure 1D). Thus, CD28 superagonistic antibodies lead to the redistribution of $\mathrm{T}$ lymphocytes from the periphery to secondary lymphoid organs.

$J J 316$ almost instantaneously abrogates $T$ cell motility in the secondary lymphoid organs of living animals. To study rapid effects of JJ316 on $\mathrm{T}$ cell motility, we performed intravital video recording of $\mathrm{T}$ cells within the spleen. Firstly, we transferred $\mathrm{CD}^{+} \mathrm{T}$ cells specific for 
A
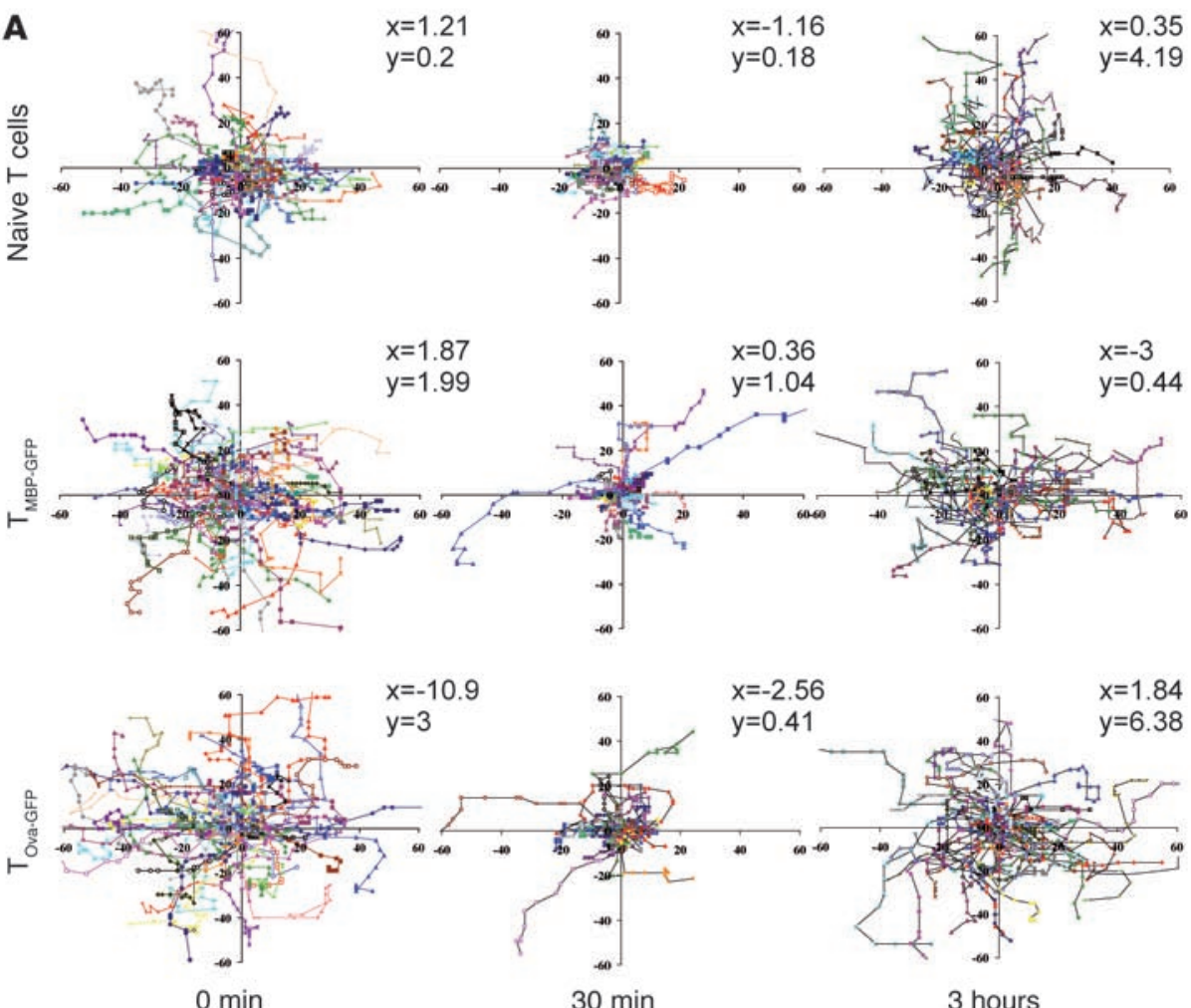

$x=-10.9$

$y=3$

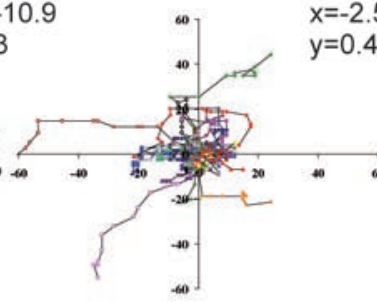

$30 \mathrm{~min}$
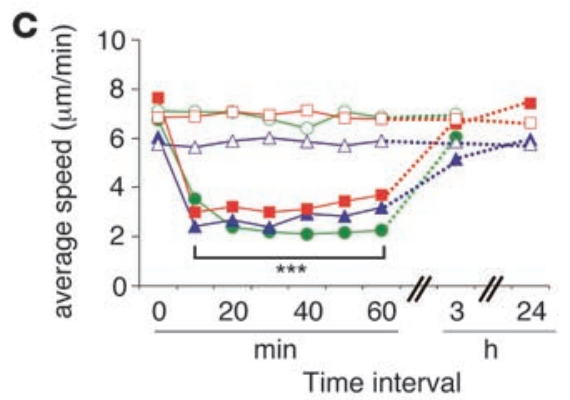

PBS

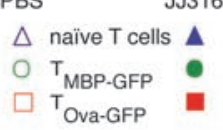

Time

\section{Figure 2}

Visualization of $\mathrm{T}$ cell arrest following JJ316 injection in vivo by intravital microscopy of living rats. (A) Fluorescently labeled $\mathrm{T}$ cell populations were adoptively transferred into rats followed by video microscopy of the spleen after 60 hours. Superimposed trajectories of 180 naive T cells, 187 $\mathrm{T}_{\text {MBP-GFP }}$ cells, and $185 \mathrm{~T}_{\text {OVA-GFP }}$ cells are displayed and recorded over a 10-minute period at the indicated time points after JJ316 treatment. The sum of $x, y$ trajectory vectors was calculated from the sum of all cell trajectories divided by the cell number. (B) The average speed of naive $T$ cells, $T_{\text {MBP-GFP }}$ cells, and T OVA-GFP $_{\text {cills }}$ in the spleen was determined within 10 minutes before and after (gray background) JJ316 or PBS treatment. $T$ cell line and 180 cells per time interval were included in the analysis of a total of 10.080 time points. Each value represents an interval of $1 \mathrm{~min}$ ute. Means of 3 independent videos are shown. (C and D) Average speed (C) and percentage of stationary cells (D) of naive T cells, $T_{\text {MBP-GFP cells, }}$ and TOVA-GFP cells after treatment with JJ316 or PBS. Video microscopy was performed at 30 second intervals, and each point represents a time interval of 10 minutes. Values represent means of 2 independent videos per treatment and $\mathrm{T}$ cell line comprising at least $240 \mathrm{~T}$ cells each. A total of 131.040 time points were analyzed. Cells were defined as stationary if they migrated less than $10 \mu \mathrm{m}$ in 10 minutes. Statistical significance was individually determined by Student's $t$ test. ${ }^{* \star} P<0.001$.

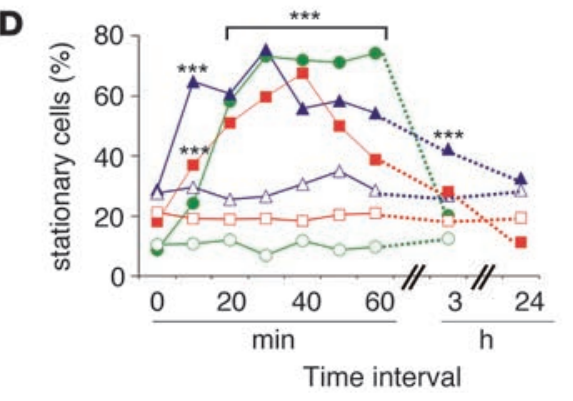

myelin basic protein (MBP), which were retrovirally engineered to express green fluorescent protein ( $\mathrm{T}_{\mathrm{MBP}-\mathrm{GFP}}$ cells) (16). As reported earlier (5), these effector $\mathrm{T}$ cells distributed throughout the red pulp and $\mathrm{T}$ cell areas in the white pulp of the spleen within 60 hours after transfer (Supplemental Figure 1; supplemental material available online with this article; doi:10.1172/JCI32698DS1). The majority of the T cells permanently moved within the tissue in a seemingly random fashion as indicated by the orientation and the low vector sum of their trajectories (Figure 2A and Supplemental Video 1). A few scattered "stationary" $\mathrm{T}$ cells displayed a confined motility and seemed to be attached to anchoring points.
Infusion of JJ316 dramatically changed the behavior of the effector T cells. Within 2 minutes most of the $\mathrm{T}_{\mathrm{MBP} \text {-GFP }}$ cells (>80\%) slowed down and reduced their average speed from $6-7 \mu \mathrm{m} / \mathrm{min}$ to $1-2 \mu \mathrm{m} / \mathrm{min}$ (Figure $2 \mathrm{~B}$ and Supplemental Video 1 ). Consecutively, their cell trajectories were shortened and the number of stationary T cells rose to $70 \%-80 \%$ (Figure 2 , A and D). Some of the $T$ cells became aggregated and began to form clusters (Supplemental Video 1). This process was completed after 3-4 minutes and remained stable for around 90 minutes. Subsequently, $\mathrm{T}$ cell motility slowly recovered and reached control levels within 3-24 hours after JJ316 infusion (Figure 2, C and D, and Supplemen- 
A


B 16
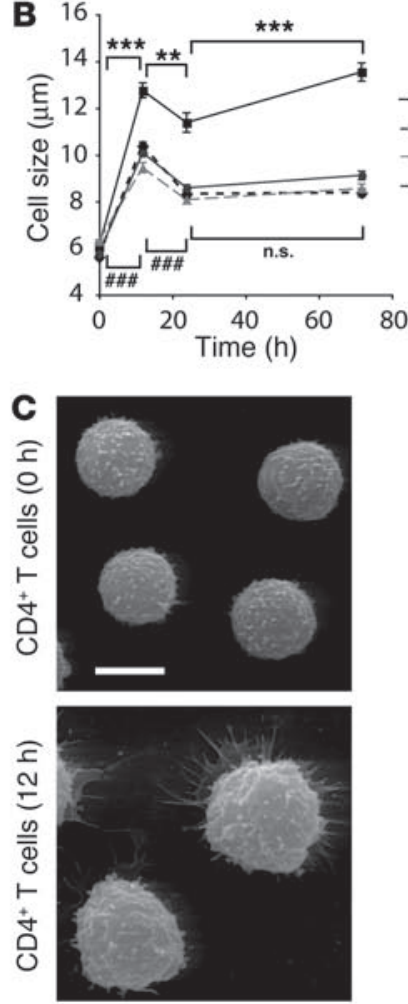

$12 \mathrm{~h}$
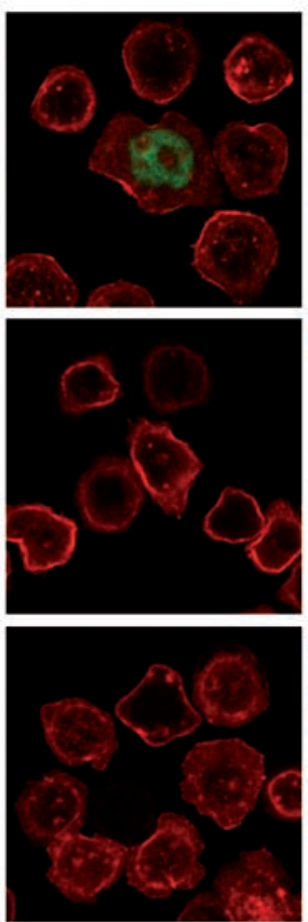

D

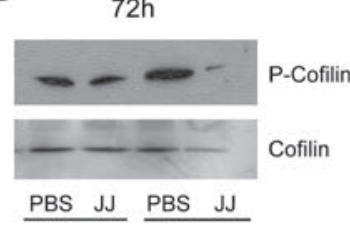

$\frac{\text { PBS JJ }}{\mathrm{CD}^{+}{ }^{+} \mathrm{CD} 25} \frac{\text { PBS } \mathrm{JJ}}{\mathrm{CD}^{+}{ }^{+} \mathrm{CD} 25^{\circ}}$

E
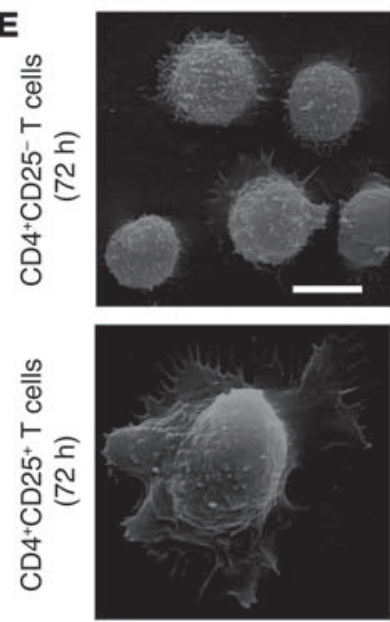

- FoxP3

$-\mathrm{CD}^{+}$

- B cells
$24 \mathrm{~h}$
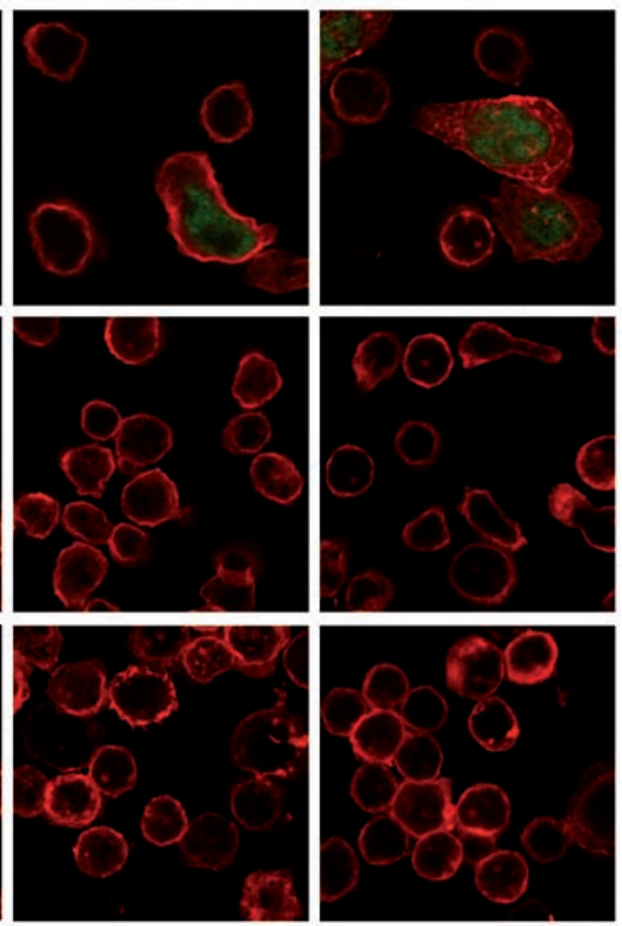
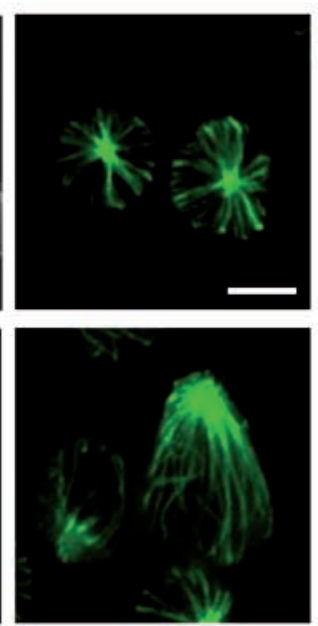

Figure 3

Analysis of JJ316-induced cytoskeletal rearrangements ex vivo by confocal microscopy and SEM. (A) $\mathrm{CD}^{+}{ }^{+} \mathrm{T}$ cells, $\mathrm{CD}^{+}$ cells, and $B$ cells were isolated at the indicated time points after treatment with $1.0 \mathrm{mg} \mathrm{JJ} 316$ and stained with phalloidin-Alexa Fluor 594 (red) to visualize F-actin polymerization. Double staining with an anti-FoxP3 antibody in combination with a secondary anti-rat Alexa Fluor 488 antibody (green) allowed distinguishing between $\mathrm{CD}^{+}{ }^{+} \mathrm{Th}$ and Tregs. Scale bar: $5 \mu \mathrm{m}$. (B) The diameters of 150 individual cells per subtype and the time point were quantified by a computeraided method; mean \pm standard error of the mean. Statistical analysis by 2-way ANOVA. The asterisks refers to the Tregs (shown on top of the graph), the pound signs to the 3 other cell types (shown below the graph). ${ }^{\star * \star} P<0.001$; \#\#\# $P<0.001$. (C) $\mathrm{CD} 4^{+} \mathrm{T}$ cells were purified before and 12 hours after JJ316 administration and analyzed by SEM. Scale bar: $5 \mu \mathrm{m}$. (D) Western blot analysis of cofilin-phosphorylation in $\mathrm{CD} 4{ }^{+} \mathrm{CD} 25^{-} \mathrm{Th}$ and CD4+CD25+ Tregs magnetically purified 72 hours after PBS or JJ316 injection. Staining with an anti-cofilin antibody served as a loading control. One representative experiment out of 3 is shown. (E) CD4+CD25- Th and CD4 ${ }^{+}$CD25+ Tregs were purified 72 hours after JJ316 administration and analyzed by SEM (left panel). Scale bar: $5 \mu \mathrm{m}$. To visualize microtubules and to study the localization of the microtubule-organizing center, Th and Tregs were stained with an anti- $\beta$-tubulin antibody (right panel). Scale bar: $5 \mu \mathrm{m}$. tal Videos 2-4). This effect of JJ316 was not dependent on the antigen specificity or the phenotype of the T cells. CD4 $4^{+}$effector $\mathrm{T}$ cells directed against ovalbumin ( $\mathrm{T}_{\mathrm{OVA-GFP}}$ cells) or freshly purified $\mathrm{T}$ cells from the spleen (consisting of $\sim 80 \%$ naive $\alpha \beta \mathrm{TCR}^{+}$ cells) behaved in all respects like $\mathrm{T}_{\mathrm{MBP} \text {-GFP }}$ cells after infusion of the CD28 superagonistic antibody (Figure 2). Furthermore, treatment with JJ316 did not affect the spatial distribution of the transferred effector T cells within the spleen (Supplemental Figure 1). These data indicate an extremely rapid but transient impact of JJ316 on $\mathrm{T}$ cell locomotion.

CD28 superagonist treatment induces rapid cytoskeletal reorganization in the absence of cellular polarization. Changes in $\mathrm{T}$ cell motility are 
often accompanied by cytoskeletal rearrangements (2). This led us to investigate the impact of JJ316 on morphological characteristics by confocal microscopy. Ex vivo analysis revealed profound activation of all lymphocyte subpopulations, including $\mathrm{CD}^{+}$ $\mathrm{T}$ cells, CD8 ${ }^{+}$cells, and B cells within 12 hours after JJ316 infusion (Figure 3A). The F-actin cytoskeleton became polymerized, the originally round cells adopted an irregular shape, and the cell size significantly increased. These changes were most pronounced in $\mathrm{CD}^{+} \mathrm{T}$ cells expressing FoxP3 (Figure 3, A and B). Interestingly, the observed cytoskeletal alterations were not accompanied by cellular polarization. Scanning electron microscopy (SEM) analysis of $\mathrm{CD} 4^{+} \mathrm{T}$ cells 12 hours after JJ316 injection revealed a round morphology and no evidence of uropod formation (Figure 3C).

While activation occurred very rapidly, it was also transient. After 24 hours, the size of most lymphocyte subtypes was significantly reduced again and remained unaltered for the entire observation period of 72 hours (Figure 3, A and B). Nevertheless, at this stage bona fide $\mathrm{CD}^{+} \mathrm{FoxP}^{+}$Tregs remained significantly enlarged and started to adopt a polarized phenotype (Figure 3, A and B). These changes became more pronounced at 72 hours after JJ316 infusion, which was confirmed by SEM analyses (Figure 3E). Purified CD4 ${ }^{+} \mathrm{CD} 25^{-}$FoxP3- Th cells exhibited only moderate morphological alterations, characterized by radially located large lamellipodia and microvilli structures. In contrast, $\mathrm{CD}^{+}{ }^{+} \mathrm{CD} 25^{+} \mathrm{FoxP}^{+}$Tregs isolated from JJ316-treated rats showed dramatic modifications such as the complete loss of microvilli, a smooth surface, and long membrane-protrusions (Figure 3E). Further immunohistochemical stainings revealed relocalization of the microtubule-organizing center (MTOC) to the trailing edge in $\mathrm{CD}^{+}{ }^{+} \mathrm{CD} 25^{+} \mathrm{FoxP}^{+}$Tregs but not $\mathrm{CD} 4^{+} \mathrm{CD} 25^{-}$FoxP3- Th cells (Figure $3 \mathrm{E})$. Flow cytometric analysis indicated that FoxP3 was indeed refined to $\mathrm{CD} 4^{+} \mathrm{CD} 25^{+} \mathrm{T}$ lymphocytes, which efficiently inhibited $\mathrm{T}$ cell proliferation in an in vitro suppression assay (Supplemental Figure 2). These data confirm that $\mathrm{CD} 4^{+} \mathrm{CD} 25^{+} \mathrm{FoxP} 3^{+} \mathrm{T}$ cells isolated from JJ316-treated rats functionally represent Tregs. Notably, these data are in line with previous studies, which demonstrated selective activation of Tregs by JJ316 (10).

The polarized shape of the Tregs after JJ316 infusion further led us to analyze cofilin dephosphorylation, which is thought to underlie F-actin remodeling and cellular polarization (17). Cofilin was strongly dephosphorylated in $\mathrm{CD}^{+} \mathrm{CD} 25^{+} \mathrm{FoxP} 3^{+}$Tregs of JJ316treated rats while the level of phospho-cofilin in $\mathrm{CD}^{+} \mathrm{CD}^{-} 5^{-} \mathrm{FoxP} 3^{-}$ Th cells was much less affected (Figure 3D). This was confirmed by densitometry, revealing $37 \% \pm 3 \%$ lower amounts of phospho-cofilin in Th cells after antibody treatment while its level was reduced by $79 \% \pm 8 \%$ in Tregs ( $n=3$; mean \pm standard error of the mean).

In vitro stimulation with JJ316 induces 2 distinct phases of activation. Administration of JJ316 in vivo leads to early morphological changes in all analyzed immune cells irrespective of their expression of the CD28 molecule. To distinguish between direct and indirect effects of JJ316, we investigated changes in lymphocyte morphology and size in vitro. Lymphocyte subpopulations were magnetically purified and stimulated with JJ316 on microscopic slides. Within 30 minutes, all $\mathrm{CD}^{+}$cells as well as the $\mathrm{CD}^{+}$ $\mathrm{T}$ lymphocytes adopted a different shape and were significantly enlarged (Figure 4, A and B). These changes, which qualitatively resemble the ones observed after application of JJ316 in vivo, were transient since lymphocyte size and morphology reverted to the original state within 2 hours (Figure 4, A and B). In contrast to T lymphocytes, B cells did not respond to JJ316 stimulation at all, supporting the argument that indirect effects must account for the activation of these cells in vivo (Figure 4, A and B). Interestingly, prolonged stimulation with the CD28 superagonistic antibody for 7 hours resulted again in the polarization and a significant increase in the size of $\mathrm{CD}^{+}{ }^{+} \mathrm{FoxP}^{+} \mathrm{T}$ cells while no such effect was seen in the other 3 subtypes (Figure 4, A and B). Notably, purified $\mathrm{CD}^{+} \mathrm{CD} 25^{+} \mathrm{T}$ cells responded in a similar way to JJ316 stimulation as the $\mathrm{FoxP}^{+}$population present in mixed $\mathrm{CD}^{+}$ $\mathrm{T}$ cell cultures (Figure 4, A and B). In line with this finding, FoxP3 expression was largely refined to the $\mathrm{CD} 4^{+} \mathrm{CD} 25^{+} \mathrm{T}$ lymphocytes and did not change in the presence of JJ316 (Figure 4C). Thus, in vitro stimulation with JJ316 clearly reflects the biphasic activation of $\mathrm{CD} 4^{+} \mathrm{CD} 25^{+} \mathrm{FoxP}^{+}$Tregs also seen in animals.

To gain insight into the signaling pathways underlying JJ316 action, we stimulated $\mathrm{CD}^{+} \mathrm{T}$ cells with $\mathrm{JJ} 316$ in the presence of kinase inhibitors and subsequently analyzed the cells for polarization as a measure of activation. Bona fide Tregs were again identified by immunohistochemical staining for FoxP3. While almost all T cells polarized within 30 minutes, the PI3K inhibitor LY294002 prevented this effect in FoxP3 ${ }^{-}$as well as in FoxP3 ${ }^{+}$cells. In contrast, the MEK inhibitor U0126 did not impact on either cell type (Figure 4D). In agreement with previous findings (18), no phosphorylation of Akt could be demonstrated after JJ316 treatment (data not shown), indicating that PI3K signaling must be mediated through an Akt-independent pathway. Our findings suggest that JJ316 induces similar signaling pathways in all $\mathrm{CD}^{+} \mathrm{T}$ cells.

JJ316 administration induces $T$ cell adhesion to fibronectin while the motility of Tregs is selectively enhanced at later time points. In view of the very transient $T$ cell arrest observed by video microscopy $(<3$ hours) and the prolonged T lymphopenia (>24 hours), we studied $\mathrm{T}$ cell adhesion to extracellular matrix components ex vivo by live imaging and confocal microscopy. We purified $\mathrm{CD}^{+} \mathrm{T}$ cells 12 hours after JJ316 treatment and studied their behavior on slides coated with fibronectin, a ligand for $\beta_{1}$ integrins (19). T cells from control animals displayed slow floating over the surface without adopting a migratory phenotype such as the formation of lamellipodia (Figure 5A). In contrast, cells isolated from JJ316-treated rats firmly attached to fibronectin, and consequently, free floating was almost completely abrogated (Figure 5A). Furthermore, we analyzed $\mathrm{CD} 4^{+} \mathrm{CD} 25^{-}$Th and $\mathrm{CD} 4^{+} \mathrm{CD} 25^{+}$Tregs isolated 72 hours after administration of JJ316. Th cells displayed only a slow movement with little sign of polarization similar to control cells (Figure $5, \mathrm{~A}$ and $\mathrm{B}$ ). In contrast, Tregs were crawling along the matrix and most cells displayed a migratory phenotype that was characterized by repeated lamellipodia formation and retraction (Figure 5B). These data indicate that JJ316 transiently increases the adhesiveness of all $\mathrm{CD}^{+} \mathrm{T}$ cells to fibronectin while it selectively enhances the motility of Tregs at later time points.

JJ316 impacts on cell adhesion molecules and interferes with T cell egress from secondary lymphoid organs. Stimulated by our finding that JJ316 increases $\mathrm{T}$ cell adhesion to fibronectin, we next studied surface expression of the proadhesive molecule, LFA-1, a $\beta 2$-integrin that is required for the firm interaction of T lymphocytes with APCs and endothelial cells (4). Flow cytometric analysis revealed a significant upregulation of LFA-1-surface expression on $\mathrm{CD}^{+} \mathrm{T}$ cells 12 hours after JJ316 infusion (Figure 6A). Additionally, we found that $\mathrm{L}$ selectin $(\mathrm{CD} 62 \mathrm{~L})$, mediating the rolling on endothelial interfaces before stable arrest and cellular extravasation (20), became almost undetectable on the cell surface of $\mathrm{CD}^{+} \mathrm{T}$ lymphocytes after 12 hours (Figure 6A). Thus, simulation with JJ316 induces 

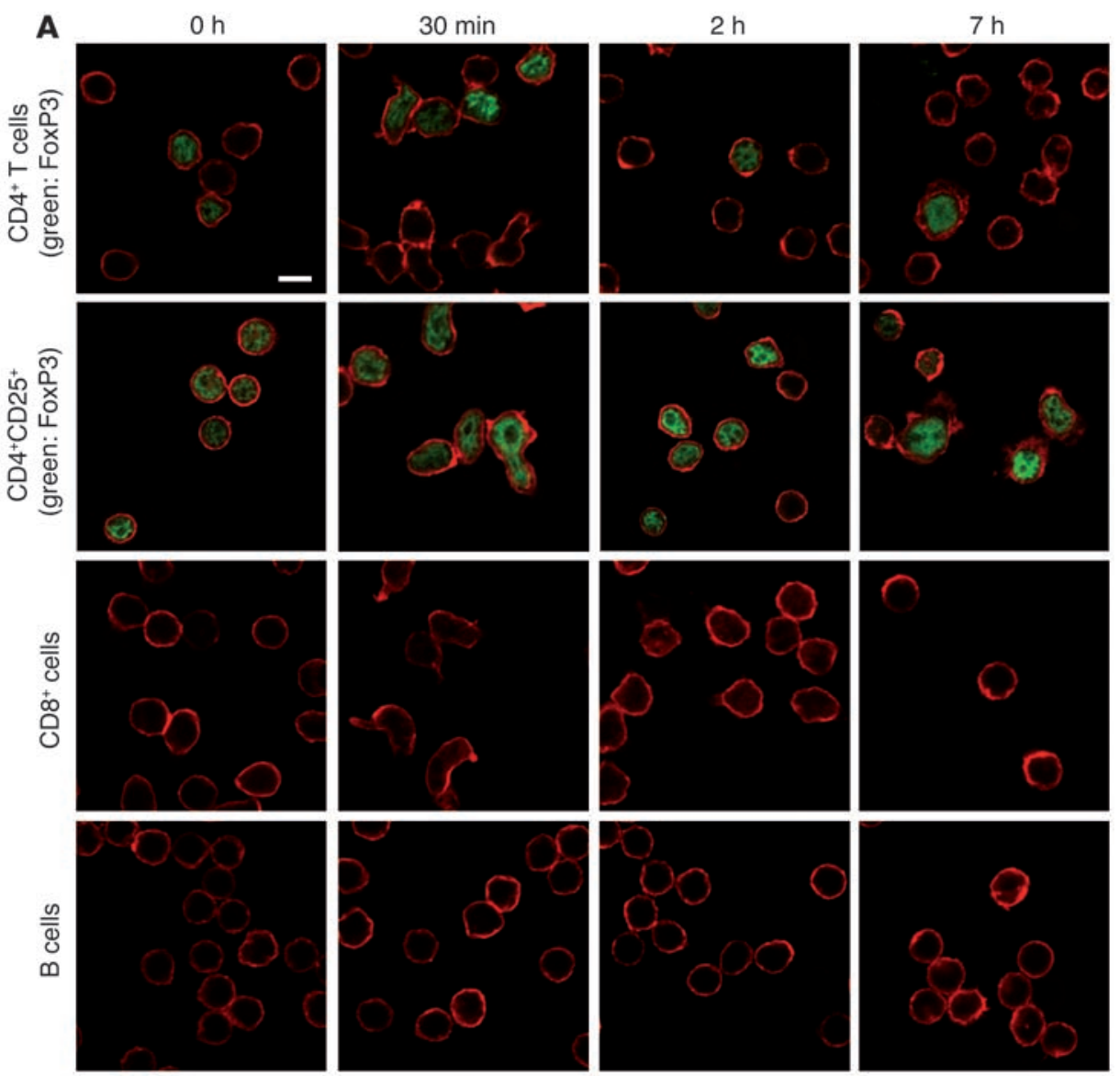

B
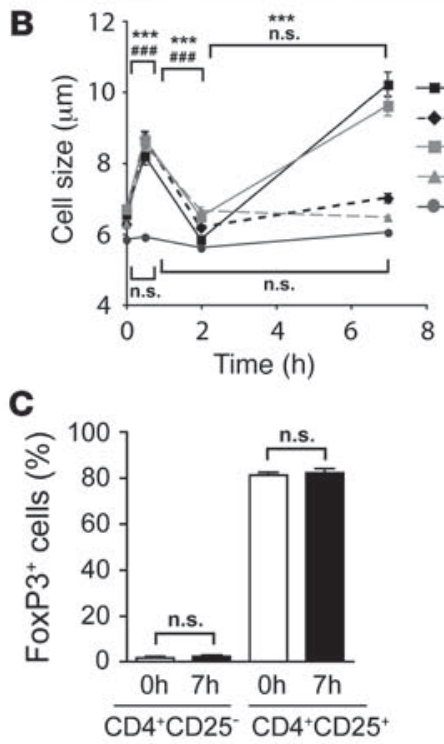

- $\mathrm{CD} 4^{+}$Foxp3 $3^{+}$

- $\mathrm{CD}^{+}{ }^{+} \mathrm{FoxP3}$

$-\mathrm{CD}^{+}{ }^{+} \mathrm{CD} 25^{+} \mathrm{FoxP3}^{+}$

$-\mathrm{CD}^{+}$

- B cells
D

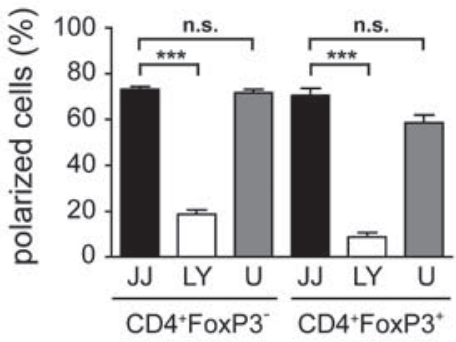

\section{Figure 4}

Analysis of cytoskeletal rearrangements after stimulation by JJ316 in vitro by confocal microscopy. (A) CD4+ T cells, CD4 ${ }^{+} \mathrm{CD}_{25}{ }^{+} \mathrm{T}$ cells, CD8 ${ }^{+}$cells, and $B$ cells were purified from naive rats and stimulated with JJ316 on microscopic slides for the indicated time periods. F-actin polymerization was visualized using phalloidin-Alexa Fluor 594, and CD4+ $T$ cell populations were additionally stained for FoxP3 expression. Scale bar: $5 \mu \mathrm{m}$. (B) The diameters of at least 150 individual cells per subtype and the time point were quantified by a computer-aided method; mean \pm standard error of the mean. Statistical analysis by 2-way ANOVA. The asterisks refers to the $\mathrm{CD}^{+}{ }^{+} \mathrm{FoxP}^{+}$ and the $\mathrm{CD} 4^{+}{ }^{+} D 25^{+}{ }^{+}$oxP $3{ }^{+}$Tregs and the pound signs to the CD4+FoxP3- Th and the $\mathrm{CD} 8^{+}$cells (both shown on the top of the graph). Changes in the size of $B$ cells are not significant (shown below the graph). (C) Magnetically purified CD4 ${ }^{+}{ }^{+}$D25- and CD4 ${ }^{+}$CD $25^{+} \mathrm{T}$ cells were stimulated as in $\mathbf{A}$. The percentage of FoxP3 ${ }^{+}$cells in both cell populations was determined before ( 0 hours) and 7 hours after JJ316 stimulation in vitro. Mean \pm standard error of the mean. Statistical analysis by Student's $t$ test. (D) CD4+ $\mathrm{T}$ cells were stimulated with JJ316 (JJ) for 30 minutes in the absence or presence of the PI3K inhibitor LY294002 (LY) or the MAPK inhibitor U0126 (U) and stained with phalloidin and an anti-FoxP3 antibody as in $\mathbf{A}$. The relative number of polarized cells is depicted in each case as a measure for activation by JJ316. Treatment and 150 individual cells per subtype were quantified by a computer-aided method; mean \pm standard error of the mean. ${ }^{* \star *} P<0.001$; \#\#\# $P<0.001$. similar changes as seen after classical costimulation through engagement of the TCR and CD28.

Next we analyzed the expression of the S1P receptor 1 (EDG-1), which mediates the egress of $\mathrm{T}$ lymphocytes from secondary lymphoid organs (21). We found that within 2 hours after JJ316 injection Edg1 mRNA levels went steeply down and remained low for around 12 hours. Subsequently, the expression slowly returned to original levels (Figure 6B). At the peak of Edg1 downregulation, i.e.,
12 hours after JJ316 infusion, the migratory capacity of T cells along an S1P gradient was virtually lost. While S1P at a concentration of $0.001 \mu \mathrm{g} / \mathrm{ml}$ induced an almost 4-fold higher transmigration index of $\mathrm{T}$ cells from control rats, the migratory capacity of $\mathrm{T}$ cells after JJ316 injection was unchanged (Figure 6C). In addition, CD69-surface expression was strongly increased after infusion of JJ316 (Figure 6D), which is in line with the recent observation that CD69 diminishes EDG-1 expression and thereby impairs S1P chemotactic func- 
$\mathbf{A}(\min ) \quad 0$


2
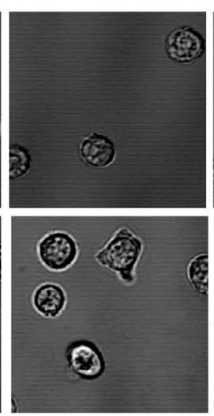

4

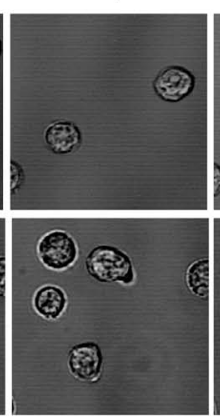

6
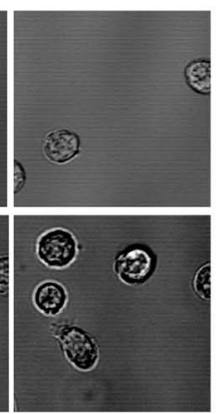

8
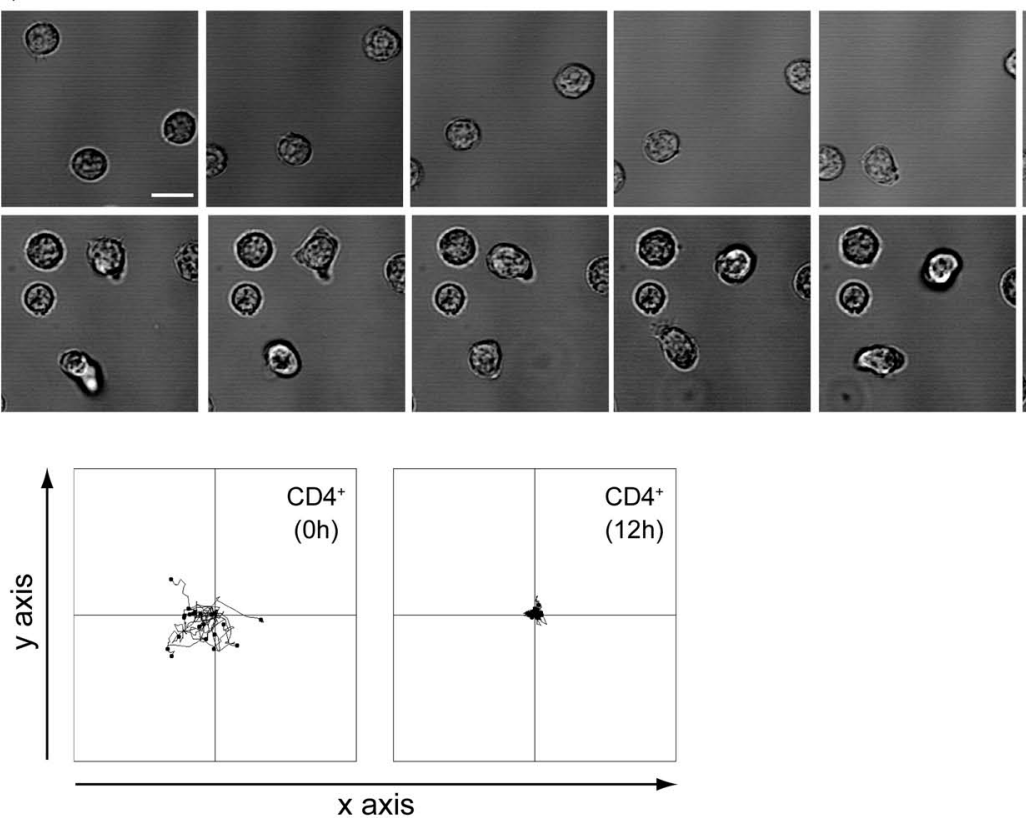

B (s) $\quad 0$
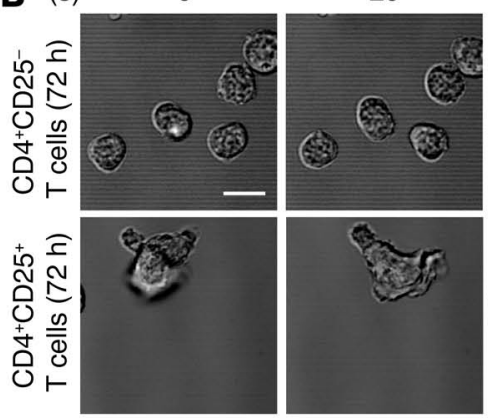

40

60

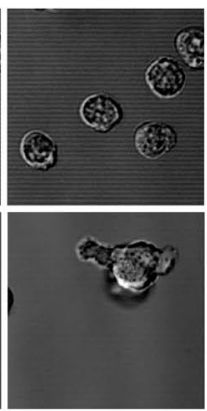

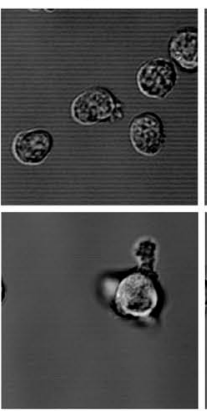

80

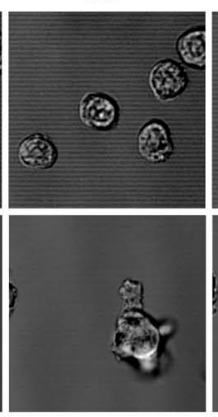

10

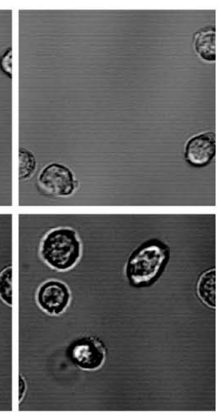

\section{Figure 5}

JJ316 strongly impacts T cell adhesion and locomotion on fibronectin ex vivo. (A) CD4+ lymph node $T$ cells were purified before and 12 hours after administration of $1.0 \mathrm{mg} \mathrm{JJ} 316$, added onto fibronectin-coated surfaces, and imaged ex vivo by confocal microscopy over a 10-minute time period. Scale bar: $5 \mu \mathrm{m}$. The migration path of 25 randomly chosen cells is shown for the tracking analysis of imaged time stacks. The graph is representative of 3 independent experiments. (B) $\mathrm{CD}^{+}{ }^{+} \mathrm{CD} 25^{-}$Th and $\mathrm{CD} 4{ }^{+} \mathrm{CD} 25^{+}$ Tregs were purified on the basis of CD25-surface expression 72 hours after injection of JJ316, added on fibronectin-coated slides, and imaged by confocal microscopy over a 10 minutes time period (only the first 100 seconds are displayed in the photographic series). Scale bar: $5 \mathrm{~mm}$. The migration path of 25 randomly chosen cells is shown for the tracking analysis. The graph is representative of 3 independent experiments.

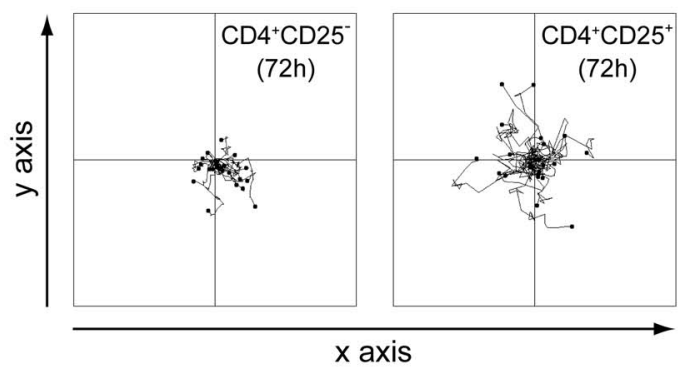

tion (22). Notably, treatment of animals with FTY720, a synthetic compound that renders $\mathrm{T}$ cells nonresponsive toward S1P (23), induced $\mathrm{T}$ lymphopenia and granulocytosis in peripheral blood with almost identical magnitude and kinetics as JJ316 (Figure 6E). This supports a potential role of S1P receptor downregulation for JJ316-induced lymphopenia and T cell redistribution.

$J J 316$ rapidly upregulates $T$ cell activation markers and proinflammatory mediators but induces only moderate cytokine release. Infusion of the CD28 superagonistic antibody TGN1412 led to strong T cell activation and a cytokine storm in human volunteers (12). Therefore we studied induction of membrane activation markers and expression of proinflammatory mediators by JJ316. Fluorescently labeled naive and effector $\mathrm{T}$ cells were adoptively transferred into wild- type rats, and 4 hours after JJ316 or PBS treatment they were reisolated from the spleen by preparative flow cytometry and analyzed by quantitative PCR. In both cell types, JJ316 induced strongly elevated mRNA expression of the proinflammatory cytokines Ifng and Il17 and the chemokines Rantes and Mcp1 as well as Il2ra (CD25) (Figure 7A). Similar effects were seen in T cells reisolated from the lymph nodes (data not shown). Furthermore, Edg1 mRNA levels were dramatically downregulated on naive and effector $\mathrm{T}$ cells (Figure 7A), confirming our previous results (Figure $5 B)$. Thus, administration of the CD28 superagonistic antibody induces broad and fulminant $\mathrm{T}$ cell activation in rats.

To confirm induction of activation markers on the protein level, we performed a flow cytometric analysis. CD25 (IL-2R $\alpha$ ) and 

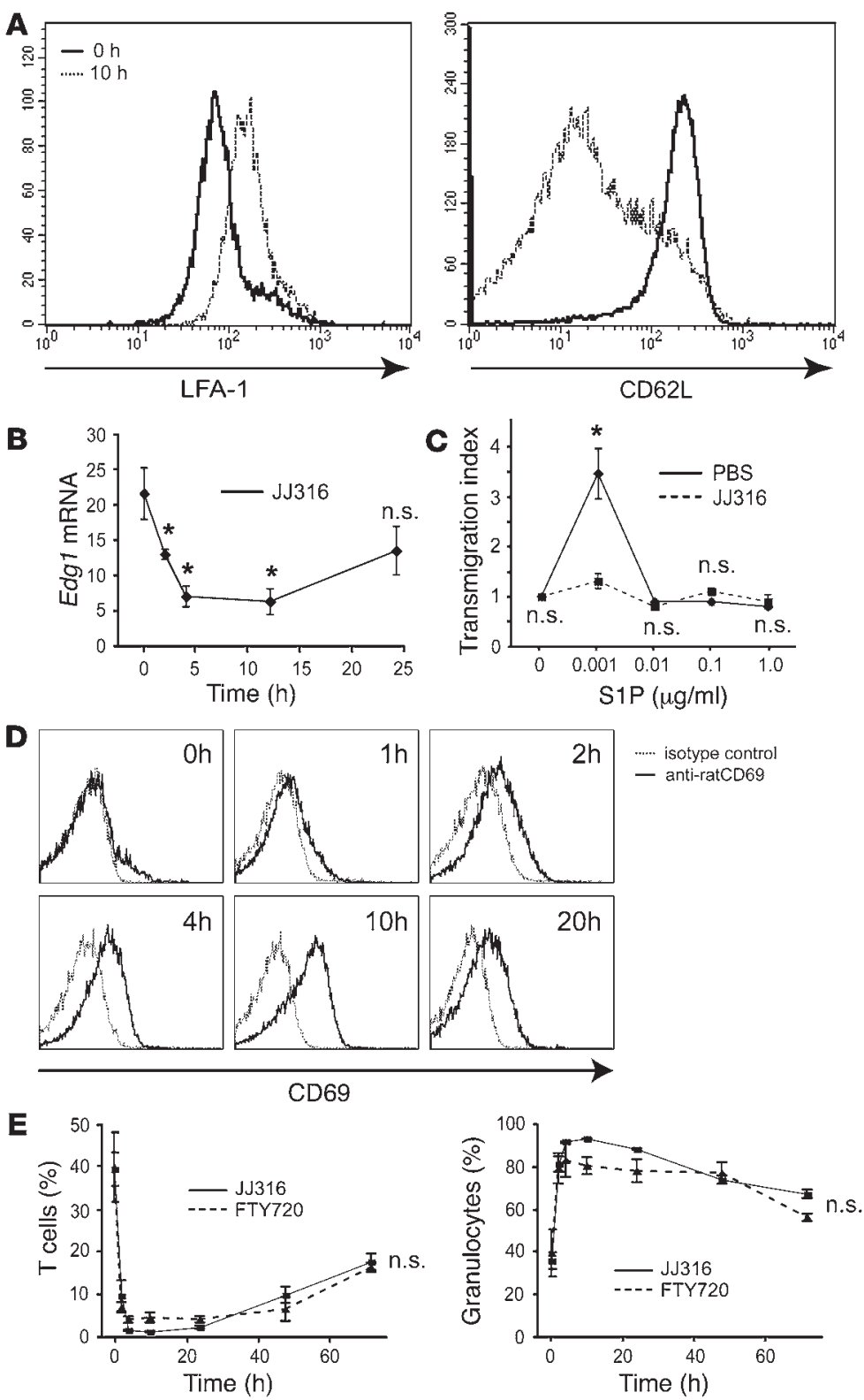

\section{Figure 6}

JJ316 induces proadhesive changes and interferes with S1P-mediated migration. (A) Lymph node cells were analyzed before and 10 hours after application of $1.0 \mathrm{mg}$ JJ316 for surface expression of LFA-1 $\left(\alpha_{L} \beta_{2}\right)$ and CD62L ( $\mathrm{L}$ selectin) on $\mathrm{CD} 4^{+} \mathrm{T}$ cells by flow cytometry. (B) $\mathrm{CD} 4^{+} \mathrm{T}$ cells were purified from JJ316-treated rats at the indicated time points and analyzed for Edg1 mRNA expression by quantitative PCR. The values were normalized to $\beta$-actin (Actb) levels. $n=4$; mean \pm standard error of the mean. ${ }^{\star} P<0.05$. (C) The chemotactic response of CD4+ $\mathrm{T}$ cells isolated 12 hours after JJ316 or PBS injection toward different concentrations of S1P was studied using a transwell migration assay. The index refers to the relative number of cells that had transmigrated after 3 hours as compared with the number of cells that passed the filter in the absence of S1P. $n=4$; mean \pm standard error of the mean. ${ }^{*} P<0.05$. (D) $\mathrm{CD}^{+} \mathrm{T}$ cells were purified from JJ316-treated rats at the indicated time points and analyzed for surface expression of CD69 by flow cytometry. Anti-mouse IgG1א was used as an isotype control. (E) Blood samples from rats i.v. injected with $1.0 \mathrm{mg} \mathrm{JJ316}$ or $0.1 \mathrm{mg}$ FTY720 were taken at the indicated time points and analyzed for the percentages of circulating $T$ cells (left panel) or granulocytes (right panel) by flow cytometry. $n=5$; mean \pm standard error of the mean. Statistical analysis was performed by comparing the 2 time courses using a 1-way ANOVA.
CD134 (Ox40) were strongly upregulated on all CD4+ $\mathrm{T}$ cells within 12 hours, thus following the transcriptional changes with some delay (Figure 7B). The effect on CD25 expression was only transient, and after 24 hours its expression level had already returned by half (Figure 7B). In contrast, expression of the chemokine receptor CXCR3 was unaffected by JJ316 at all time points as revealed by confocal microscopy (data not shown). Most surprisingly, however, only very moderately elevated serum levels of the proinflammatory cytokines TNF $\alpha$ and IFN $\gamma$ were measured within the first 24 hours after JJ316 treatment while MCP-1 was not detectable at all (Figure $7 \mathrm{C}$ and data not shown). Notably, the serum concentrations reached by CD28 superagonist treatment in rats were 2 to 3 orders of magnitude lower as compared with those measured after injection of a nonlethal dose of LPS (Figure 7C). A lower dose of 0.2 $\mathrm{mg} J \mathrm{~J} 316$ did not result in any detectable TNF $\alpha$ and IFN $\gamma$ release into the serum at all (data not shown), although it caused marked $\mathrm{T}$ lymphopenia (Figure 1A). In addition, we never observed any signs of discomfort in rats treated with JJ316, such as scrubby fur, diminished locomotion, or reduced food uptake. Morphological analysis of major organs failed to reveal any pathological effect of JJ316 treatment. Thus, despite strong $T$ cell activation, systemic cytokine release is very limited after JJ316 administration and therefore, constitutes a major difference between rats and humans.

\section{Discussion}

CD28 superagonistic antibodies have the unique ability to address $\mathrm{T}$ cells in the absence of concurrent TCR ligation (7). Previous analyses had suggested that this leads to the preferential expansion of Tregs as compared with other T cells (8). Whereas this characteristic is thought to underlie the remarkable efficiency of such antibodies in the treatment of autoimmune diseases in rodents $(10,11)$, a recent clinical trial led to devastating side effects in 6 human volunteers (12). This raised the question of whether the rapid effects were unique to the human system or whether the 
A
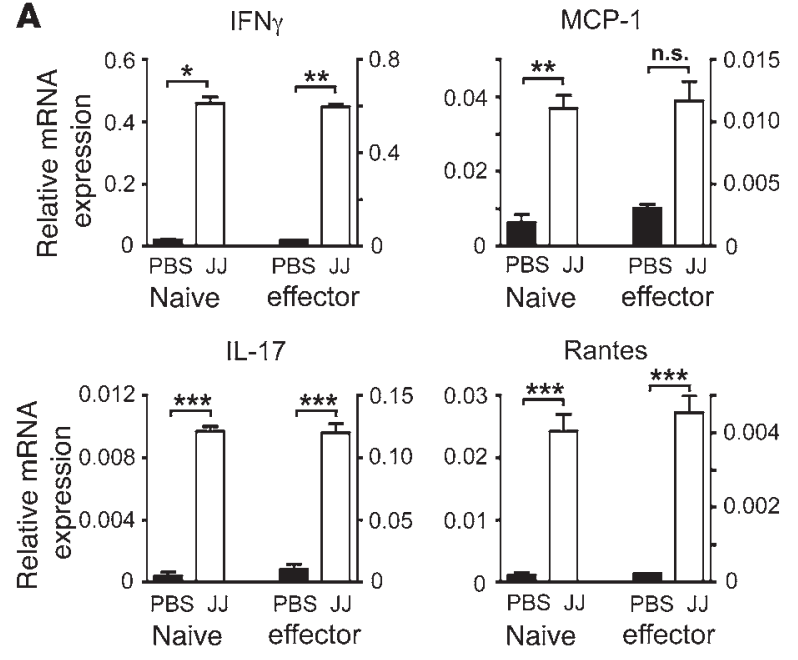

B
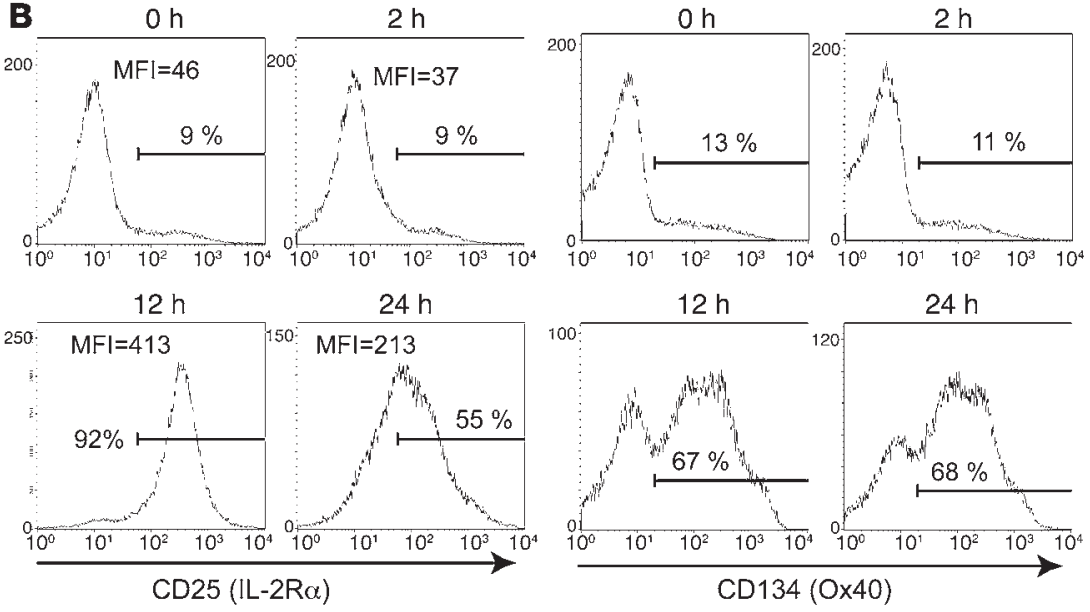
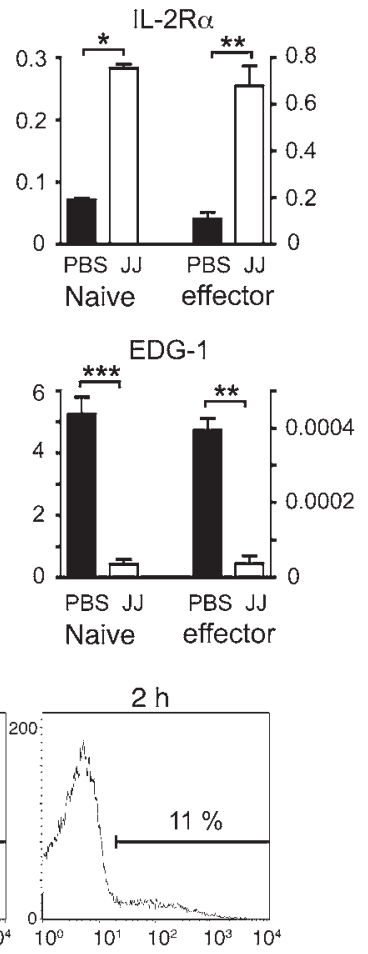
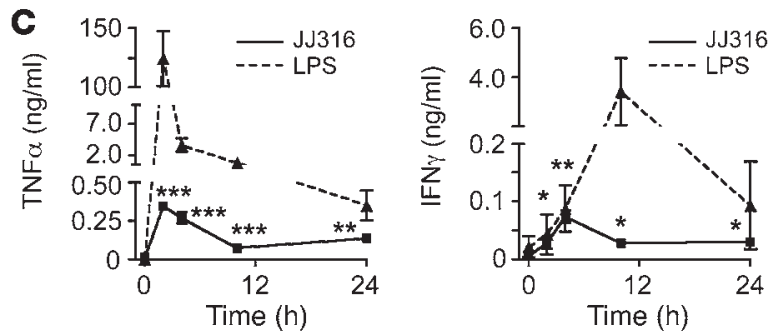

rodent CD28 superagonistic antibody induces similar changes. Our results indicate that JJ316 led to a redistribution of T cells to secondary lymphoid organs and thereby induced $\mathrm{T}$ lymphopenia, which is reminiscent of the effects of TGN1412 in healthy volunteers. In contrast to the clinical trial in humans, we were now able to study the mechanisms underlying lymphocyte redistribution after CD28 superagonist injection in detail. Within 10 hours, $\mathrm{CD}^{+} \mathrm{T}$ cell counts in liver and lung dropped dramatically while their numbers remained unaffected in spleen and lymph nodes. This was confirmed by our finding that the CD28 superagonistic antibody did not induce a memory phenotype as well as by tracking experiments showing that $\mathrm{CD} 4^{+} \mathrm{T}$ cells were depleted from the extralymphoid organs after JJ316 treatment. In contrast, B cell homing was only marginally affected. Our finding that the cellularity of the secondary lymphoid organs was not increased despite the redistribution of $\mathrm{T}$ cells from peripheral tissues can be explained by the low absolute number of blood-residing lymphocytes (24) and a modest induction of T cell apoptosis by JJ316 (data not shown). In summary, CD28 superagonistic antibodies have the ability to trap $\mathrm{T}$ cells in the secondary lymphoid organs.

$\mathrm{T}$ lymphopenia occurs remarkably rapidly and is maintained over a 24-48 hours period. Indeed, intravital video microscopy revealed that $\mathrm{T}$ cells were almost instantaneous arrested in spleen and lymph nodes of living animals following JJ316 injection. Within 2 minutes, their velocity dropped dramatically and the number of stationary cells increased to around $80 \%$. These data suggest that $\mathrm{T}$ cells become trapped in secondary lymphoid organs immediately after administration of the CD28 superagonistic antibody as a consequence of their reduced motility. However, since locomotion in situ was restored a few hours after antibody administration, 
additional changes must occur in T cells explaining the prolonged lymphopenia for more than 24 hours. We have identified a number of mechanisms that presumably contribute to this effect. Firstly, we observed cytoskeletal rearrangements that include F-actin polymerization and an extensive increase in cell size but no cellular polarization occurred similar to that seen after antigen challenge (2). Secondly, the $\beta_{2}$ integrin LFA- 1 was upregulated while L selectin expression was reduced by JJ316. These are typical changes that were also induced upon costimulation of antigen-specific $\mathrm{T}$ cells and strengthened the interaction with APCs while interfering with lymphocyte recirculation. Using a functional assay, we could further show that $\mathrm{T}$ cell interaction with fibronectin was strongly enhanced by JJ316. Since fibronectin is a ligand for $\beta_{1}$ integrins, the observed firm adhesion could also contribute to the impaired $T$ cell recirculation. Thus, several mechanisms might be involved in promoting the trapping of $\mathrm{T}$ cells in the secondary lymphoid organs. In addition, our findings revealed that CD28 superagonistic antibodies not only retained $\mathrm{T}$ cells in spleen and lymph nodes but also interfere with $\mathrm{T}$ cell egress. This is mainly mediated through EDG-1, the S1P receptor that is predominantly expressed on $\mathrm{T}$ lymphocytes and guides their egress from thymus and secondary lymphoid organs in response to S1P present at elevated levels in the circulation (21). We could show that JJ316, similar to costimulation of antigen-specific cells, strongly downregulates EDG-1 levels on T lymphocytes, which impairs their ability to migrate along a S1P gradient. This is presumably the consequence of increased CD69-surface expression following infusion of the CD28 superagonistic antibody and closely resembles the effects of FTY720, a S1P receptor antagonist that is presently tested for its application in the treatment of inflammatory conditions in humans (25). Our experiments confirmed that induction of T lymphopenia by JJ316 and FTY720 occurs with similar kinetics and magnitude, indicating that EDG-1 might indeed account for the prolonged trapping of $\mathrm{T}$ cells in spleen and lymph nodes. Taken together, we suggest that impaired egress from secondary lymphoid organs, in combination with increased cell-cell and cellmatrix interactions, underlies at least in part the prolonged $\mathrm{T}$ lymphopenia induced by CD28 superagonistic antibodies.

In addition to the proadhesive alterations, JJ316 also strongly induced expression of membrane activation markers and proinflammatory mediators. Within a few hours after antibody infusion, mRNA expression of the cytokines Ifng and Il17, the chemokines Mcp1 and Rantes as well as of Il2ra was dramatically elevated in both, naive and effector T cells. This indicates broad and fulminant $\mathrm{T}$ cell activation and is in agreement with our previous observation that IFN $\gamma$ is upregulated after in vitro stimulation with JJ316 (10). With some delay, cell-surface expression of CD25 (IL-2R $\alpha$ ), CD69, and CD134 (Ox40) were also strongly enhanced by JJ316. Surprisingly, however, the concentrations of TNF $\alpha$ and IFN $\gamma$ in the serum of rats treated with JJ316 were only very moderately increased while MCP-1 was not detectable at all. Importantly, peak cytokine concentrations were 2 to 3 orders of magnitude below the levels achieved by injection of a nonlethal dose of LPS and were not accompanied by notable abnormalities in the appearance, behavior, or organ morphology of the rats $(12,26)$. At a 5-fold lower dose of JJ316, cytokines could not be measured in the serum at all. This suggests that secretion rather than the synthesis of proinflammatory mediators constitutes the main difference between rats and humans and confirms that the massive cytokine storm encountered in the clinical trial could not have been foreseen on the basis of experiments in rodents. However, it is noteworthy that such studies are generally performed in young animals that grow up under virtually pathogen-free conditions. For that reason we additionally tested diabetes-prone BB rats, 6- to 9-month-old Lewis rats, and rats that had suffered from EAE but were unable to identify any pathological effects of JJ316 (data not shown). Nevertheless, we are fully aware that these conditions still do not compare by any means to human adults having experienced 20 years of recurrent infections.

While systemic cytokine levels are definitively low, it is still conceivable that their local concentrations are elevated. Possibly, such an effect could contribute to the activation of bystander cells such as B lymphocytes that are unable to directly respond to CD28 engagement. In line with this notion, we have found extensive cytoskeletal rearrangements and a strong increase in the size of B cells isolated from JJ316-treated rats. However, stimulating B cells in culture with JJ316 did not induce any alterations.

Interestingly, the first wave of T cell activation induced by CD28 superagonistic antibodies is transient in nature. Within 24-48 hours, the changes in cell size, F-actin polymerization, CD25 expression, and the increased adhesion to fibronectin disappeared in most lymphocytes. In contrast, $\mathrm{CD} 4^{+} \mathrm{CD} 25^{+} \mathrm{FoxP} 3^{+}$bona fide Tregs experienced a second activatory phase at this stage. Their morphology changed from an unpolarized to a polarized phenotype and after 3 days, the difference in size and motility between Treg and Th cells was quite remarkable. As shown previously, Tregs also proliferate more vigorously at this time point, leading to their strong enrichment (11). Thus, a first wave of phenotypic alterations affecting all lymphocytes is followed by a second wave of effects that preferentially pertains to Tregs. While these 2 phases are not clearly intercepted in vivo, our in vitro analyses are clearly in support of such a notion. All T cells were rapidly activated by JJ316, but their size returned to basal levels after 2 hours. Subsequently, preexisting $\mathrm{CD} 4{ }^{+} \mathrm{CD} 25^{+} \mathrm{FoxP} 3^{+}$bona fide Tregs experienced a second phase of activation characterized by a marked increase in size while the other $\mathrm{T}$ cell subtypes did not respond any longer. FoxP3 expression remained unaffected by the CD28 superagonistic antibody during the course of the experiment. Nevertheless, it does not appear that different signal transduction pathways are engaged by JJ316 in Th as compared with Tregs (27). Our results rather suggest that the first activation phase is similar in all $\mathrm{T}$ cell subpopulations, as reflected by their similar phenotypic changes. Moreover, based on our in vitro findings, the PI3K, but not the MEK pathway, is engaged by JJ316 irrespective of the CD4+ $\mathrm{T}$ cell subset. Thus, early activation by JJ316 is most likely mediated through the same signaling pathway in all $\mathrm{T}$ cells. In contrast, the second activatory phase in Tregs could be a result of their continued expression of CD25 and consequently their ability to respond to IL-2 while CD25 expression is downregulated on the other $\mathrm{T}$ cell subsets within 24 hours. Alternatively, the CD28 complex is less rapidly modulated in Tregs as compared with the other $\mathrm{T}$ cell subsets, resulting in more sustained signaling and the observed second activation phase. Finally, cytokines that may locally be released after JJ316 stimulation could preferentially act on Tregs, thereby, inducing their restimulation. This, however, could only be tested in knockout models that are not available in rats. In summary, CD28 superagonistic antibodies cause a biphasic activation of $\mathrm{T}$ cells despite apparently inducing similar signaling pathways.

We believe that our observations contribute to a better understanding of what happened during the clinical trial of TGN1412 in 
March 2006 (12). We assume that the rapidly occurring effects of the humanized CD28 superagonistic antibody were a consequence of the first wave of $\mathrm{T}$ cell activation, with the exception that rats do not experience a massive cytokine storm. During the second wave of $\mathrm{T}$ cell activation, the effects of $\mathrm{CD} 28$ superagonistic antibodies on Tregs dominate and are likely to account for the beneficial effects observed in rodent models of autoimmune diseases. Therefore, these antibodies are a 2 -sided sword and require extensive investigation before they may be successfully applied to humans.

\section{Methods}

Animal experimentation. Lewis rats were bred in our own animal facility and kept in individually ventilated cages. Male rats were used for experimentation at an age of 8 weeks $(\approx 250 \mathrm{~g})$. JJ316 (dissolved in $0.3 \mathrm{ml} \mathrm{PBS}$ ) and FTY720 (dissolved in $0.1 \mathrm{ml} \mathrm{50 \%} \mathrm{EtOH}$ ) were injected into the tail vein, and LPS (serotype 0111:B4) was injected i.p. at a concentration of $4 \mathrm{mg} / \mathrm{kg}$. To track lymphocytes in vivo (see Figure 1D), they were purified from donor rats and labeled with $5 \mu \mathrm{M}$ CFSE for 8 minutes at room temperature. Cells $\left(4 \times 10^{7}\right.$ per rat) were injected into the tail vein under deep anesthesia. To study resident leukocytes in lung and liver, the rats were perfused with PBS prior to dissecting these organs. The procedures for performing animal experiments as well as animal care were in accordance with the principles of the Bavarian and Lower Saxony state regulations and approved by the Regierung von Unterfranken (Würzburg, Germany), the Regierung von Oberbayern (Munich, Germany), and the Niedersächisches Landesamt für Verbraucherschutz und Lebensmittelsicherheit (Oldenburg, Germany).

Antibodies and reagents. The following antibodies were used for immunofluorescence and western blotting: anti-phospho-cofilin (Ser3) from Cell Signaling, anti-cofilin (N19) and anti-rabbit-HRP from Santa Cruz, anti$\beta$-tubulin (TUB2.1) from Sigma-Aldrich, anti-FoxP3 (FJK-16a) from eBiosciences, anti-rabbit/rat/mouse Alexa Fluor 488/594 and phalloidin-Alexa Fluor 488/594 from Molecular Probes, and anti-goat-HRP from Dianova. Antibodies against cell-surface molecules used for flow cytometry were obtained from BD Pharmingen: CD4 (Ox38), CD8 $\alpha$ (Ox8), CD25 (Ox39), CD45RC (Ox22), CD134 (Ox40), CD62L (HRL1), $\beta$-TCR (R73), granulocyte antigen (His48), LFA-1/CD11a (WT.1), Thy-1 (Ox7), RT6.1 (P4/16), CD69 (Yuggu-F6; kindly provided by Jung-Hyun Park, NIH, Bethesda, USA). Poly-L-lysine, S1P, LPS, CFSE, LY294002, and U0126 were purchased from Sigma-Aldrich, fibronectin from TebuBio, FTY720 from Biozol, and CMTMR [5-(and-6)-(((4-chloromethyl)benzoyl)amino)tetramethyl-rhodamine] from Invitrogen. JJ316 is derived from a hybridoma cell line and was provided by Thomas Hünig (University of Wuerzburg).

Magnetic cell sorting. Single-cell suspensions were prepared from lymph nodes or spleen followed by magnetic cell sorting using an AutoMacs machine (Miltenyi) as previously described (10). CD4 ${ }^{+} \mathrm{T}$ cells were obtained by depleting B cells (Ox33), $\gamma \delta$ T cells (V65), NK cells (10/78), and CD8 $\alpha$ cells (Ox8). Th and Tregs were further separated by positive selection for $\mathrm{CD} 25$ expression (Ox39); the purity of both subpopulations was greater $90 \%$ based on flow cytometric analysis of FoxP3. The same strategy was employed to isolate CD8 $\alpha^{+}$cells and B cells, with the exception that Ox35 (specific for $\mathrm{CD}^{+}{ }^{+}$cells) was substituted for $\mathrm{Ox} 8$ or Ox33, respectively.

FACS analysis. Lymphocytes were isolated by passing the freshly isolated organs through a $40 \mu \mathrm{m}$ nylon mesh, washed in FACS buffer (PBS with $0.5 \% \mathrm{BSA}$ and $0.05 \% \mathrm{NaN}_{3}$ ), counted, and stained using various antibody combinations. In case of liver and lung, the lymphocytes were isolated by density centrifugation following perfusion with $\mathrm{NaCl}$. The dissected tissue was passed through a metal mash, and after centrifugation the homogenate was resuspended in $28 \mathrm{ml}$ of $40 \%$ Percoll, overlaid on $12 \mathrm{ml}$ of $80 \%$ Percoll, and spun for 20 minutes $\left(950 \mathrm{~g} ; 4^{\circ} \mathrm{C}\right)$. Finally, the lymphocytes were harvested at the interface between the layers. To remove erythrocytes, blood samples were treated with OptiLyse (Beckman Coulter) after staining. Analysis by 4- and 6-color flow cytometry was performed using a BD FACSCalibur or a BD FACSCantoII machine, respectively, in combination with DiVa and CELLQUEST software.

Intravital imaging of T cell locomotion. $\mathrm{CD}^{+}$effector $\mathrm{T}_{\mathrm{MBP}-\mathrm{GFP}}$ and $\mathrm{T}_{\mathrm{OVA}-\mathrm{GFP}}$ cell lines were established and tested for their phenotype and antigen specificity as reported previously (16). Splenic T cells, containing greater than $80 \%$ naive lymphocytes, were purified by depleting monocytes/macrophages (Ox42) and B cells (Ox33). Then, they were labeled with $3 \mu \mathrm{M}$ of the red fluorescent dye, CMTMR, by incubating the cells for 20 minutes at $37^{\circ} \mathrm{C}$. For intravital imaging, $3 \times 10^{6}$ splenic CMTMR ${ }^{+} \mathrm{T}$ cells were coinjected with $5 \times 10^{6} \mathrm{GFP}^{+}$ effector $\mathrm{T}$ cells. Intravital imaging was performed 60 hours later.

Animals were anesthetized and preparation of the spleen was performed as described previously (5). Video time-lapse recordings were performed using an inverted microscope (Axiovert 200M; Zeiss) equipped with a $20 \times 0.4$ NA objective (Zeiss). A Coolsnap-HQ camera (Photometrics) was used to acquire images in 30-second intervals. MetaMorph (Visitron Systems) software was used for processing the data. Cell trajectories and velocities were evaluated as described previously (5) using ImageJ software (http://rsb.info.nih.gov/ij/).

Immunofluorescence analysis by laser scanning confocal microscopy. Freshly isolated $\mathrm{T}$ cells were attached on poly-L-lysine-coated 8-well chamber slides (Nunc) for 20 minutes at $37^{\circ} \mathrm{C}$ at a density of $3 \times 10^{5}$ cells in $100 \mu \mathrm{l}$ medium per chamber. After adding $4 \%$ PFA for 10 minutes, the cells were permeabilized with $0.01 \%$ Triton-X100 for 5 minutes, blocked with $5 \%$ BSA, and incubated with an anti-FoxP3 antibody diluted in 1\% BSA overnight at $4^{\circ} \mathrm{C}$. After washing, the samples were stained with anti-rat Alexa Fluor 488 secondary antibody, together with phalloidin-Alexa Fluor 594 for 45 minutes at room temperature. The slides were mounted with Fluoromount-G medium (Southern Biotech) and analyzed by confocal microscopy. For visualizing tubulin structures, T cells were fixed with PHEMO-fix $(3.7 \%$ Paraformaldehyd, $0.05 \%$ Glutaraldehyd, $0.5 \%$ Triton-X100 in PHEMO buffer) for 10 minutes at $37^{\circ} \mathrm{C}$, washed twice with PHEMO buffer $(68 \mathrm{mM}$ PIPES, 25 mM HEPES, pH 6.9, 15 mM EGTA, $3 \mathrm{mM} \mathrm{MgCl}_{2}, 10 \%$ DMSO) at $37^{\circ} \mathrm{C}$, followed by $50 \mathrm{mM} \mathrm{NH}_{4} \mathrm{Cl}$ and PBS. Subsequently, the cells were stained with an anti- $\beta$-tubulin antibody. Imaging was performed using a Zeiss LSM 410 Meta confocal microscope equipped with $63 \times$ oil objective (numeric aperture 1.4) and laser lines 488 and 543. Image acquisition was performed with Zeiss LSM software $3.2 \mathrm{SP} 2$. For each quantification, 100-200 individual cells were randomly chosen and analyzed.

In vitro stimulation of lymphocyte subsets. Eight-well chamber slides were coated with $5 \mu \mathrm{g} / \mathrm{ml}$ sheep anti-mouse IgG for 1 hour at $37^{\circ} \mathrm{C}$. Slides without anti-mouse IgG were used as control. We incubated $3 \times 10^{6} \mathrm{cells} / \mathrm{ml}$ with $10 \mu \mathrm{g} / \mathrm{ml} \mathrm{JJ3} 16$ for 1 hour on ice, and $100 \mu \mathrm{l}$ of each cell suspension was incubated at $37^{\circ} \mathrm{C}$ on prewarmed slides. Stimulation was stopped by adding 4\% PFA for 10 minutes, followed by immunofluorescence staining. To analyze the impact of kinase inhibitors, $\mathrm{T}$ cells were preincubated with $30 \mu \mathrm{M} \mathrm{LY} 294002$ or $10 \mu \mathrm{M}$ U0126 for 20 minutes at $37^{\circ} \mathrm{C}$ and cooled on ice, followed by JJ316 incubation as described above.

Scanning electron microscopy. Purified T cells were settled on Poly-L-Lysine coated coverslips $(12 \mathrm{~mm})$ in a 24-well plate at a density of $2 \times 10^{6} \mathrm{cells} / \mathrm{ml}$, fixed with $6.25 \%$ Glutaraldehyd in $50 \mathrm{mM}$ phosphate buffer, $\mathrm{pH} 7.2$, for 10 minutes at room temperature, and subsequently, incubated overnight at $4^{\circ} \mathrm{C}$. After washing with phosphate buffer, the samples were dehydrated stepwise in acetone, critical-point dried, and sputtered with platin/palladium. Cells were investigated by SEM analysis, using a Zeiss DSM 962 scanning electron microscope.

Fibronectin induced locomotion. For ex vivo live cell imaging, 6-channel $\mu$-slides VI (ibidi) were coated with $20 \mu \mathrm{g} / \mathrm{ml}$ fibronectin in PBS, containing $\mathrm{MgCl}_{2} / \mathrm{CaCl}_{2}$, overnight at $4^{\circ} \mathrm{C}$. Slides were washed with PBS and blocked 
with $2.5 \% \mathrm{BSA}$ at $37^{\circ} \mathrm{C}$, washed again with PBS, kept in $0.5 \% \mathrm{BSA}$ at $4^{\circ} \mathrm{C}$, and prewarmed before analysis. Purified T cells were resuspended in $0.5 \%$ BSA. Imaging was immediately started after adding $1 \times 10^{5} \mathrm{~T}$ cells in a volume of $30 \mu \mathrm{l}$ into a channel at a 1 minute time frame for 10 minutes. The temperature of the samples was maintained at $37^{\circ} \mathrm{C}$ using an objective table heater. Data analysis of time stacks was performed using ImageJ software and plugins for manual tracking and chemotaxis (http://rsb.info.nih.gov/ij/).

S1P chemotaxis assay. The response of $\mathrm{T}$ cells to S1P was studied using $6.5 \mathrm{~mm}$ transwell inserts with a $3 \mu \mathrm{m}$ pore size (Costar). T cells were resuspended in RPMI $/ 0.5 \%$ fatty acid free BSA. To assess chemotaxis, $1 \times 10^{6}$ $\mathrm{T}$ cells in $100 \mu \mathrm{l}$ volume were placed into each insert. The lower wells of a 24-well plate were filled with $600 \mu \mathrm{l}$ RPMI/0.5\% fatty acid free BSA containing the indicated concentrations of S1P. After 3 hours at $37^{\circ} \mathrm{C}$, T cells that had transmigrated into the lower well were harvested and counted using CaliBRITE beads (BD Biosciences) by flow cytometry.

Cytokine bead array. Cytokine serum levels were determined by Cytometric Bead Array (BD Biosciences). Diluted serum (50 $\mu$ l) was incubated with beads specific for IFN $\gamma$ and TNF $\alpha$ according to the manufacturer's instructions. The total amount of cytokines was determined using a BD FACSCalibur or a BD FACSCantoII machine and analyzed using the FCAP Array 1.0 software (Soft Flow).

Quantitative PCR. Quantitative PCR was performed using an iCycler (BioRad) or an ABI Prism 5700 instrument (Applied Biosystems) according to established protocols $(5,28)$. The cDNA was synthesized by oligo(dT) priming starting from $1.0 \mu \mathrm{g}$ of total RNA as previously described, amplified using specific primers, and normalized to the amount of the housekeeping gene Actb (29). Data were obtained by independent duplicate measurements.

Western blot analysis. T cells were centrifuged and lysed in denaturing sample buffer. After mechanical shearing of DNA, lysates were heated at $95^{\circ} \mathrm{C}$ for 5 minutes and separated on a $10 \%$ SDS-PAGE gel. After transfer, the PVDF membrane was stained with the indicated primary antibodies, visualized with an HRP-conjugated secondary antibody, and developed using ECL as chemiluminescence substrate (Pierce).

Statistics. Comparison of multiple experimental groups was performed by 2-way ANOVA followed by a post-hoc Bonferroni multiple comparison test (Figure $3 \mathrm{~B}$ and Figure $4 \mathrm{~B}$ ). Individual time courses were compared using the repeated measure ANOVA followed by a post-hoc Bonferroni multiple comparison test (Figure 1A and Figure 6D). To compare 2 experimental conditions, the Student's $t$ test was employed (Figure 1, B and D, Figure 2, B-D, Figure 6, B and C, and Figure 7, A and C). Differences in lymphocyte subtype composition were analyzed using the $\chi^{2}$ test (Figure 1C). $P<0.05$ was considered significant.

\section{Acknowledgments}

We would like to thank Christian Bauer and Katrin Voss for excellent technical help, Georg Krohne from the Division of Electron Microscopy (University of Wuerzburg) for support with the SEM analysis, Andreas Weishaupt for help with animal experimentation, and Thomas Hünig for scientific discussion. This work was supported by grants from DFG (Re1631/1-3 to H.M. Reichardt and SFB455 to A. Flügel), Wilhelm Sander-Stiftung (2003.129.2), IZKF Wuerzburg, and Gemeinnützige Hertie-Stiftung (1.01.1/06/010 to H.M. Reichardt and 1.01.1/04/010 to A. Flügel).

Received for publication May 15, 2007, and accepted in revised form January 30, 2008.

Address correspondence to: Holger M. Reichardt, University of Göttingen Medical School, Department of Cellular and Molecular Immunology, Humboldtallee 34, 37073 Goettingen, Germany. Phone: 49-551-393365; Fax: 49-551-395843; E-mail: hreichardt@ med.uni-goettingen.de.
1. Riley, J.L., and June, C.H. 2005. The CD28 family: a T-cell rheostat for therapeutic control of T-cell activation. Blood. 105:13-21.

2. Billadeau, D.D., Nolz, J.C., and Gomez, T.S. 2007. Regulation of T-cell activation by the cytoskeleton. Nat. Rev. Immunol. 7:131-143.

3. Jung, T.M., Gallatin, W.M., Weissman, I.L., and Dailey, M.O. 1988. Down-regulation of homing receptors after $\mathrm{T}$ cell activation. J. Immunol. 141:4110-4117.

4. Pribila, J.T., Quale, A.C., Mueller, K.L., and Shimizu, Y. 2004. Integrins and T cell-mediated immunity. Annu. Rev. Immunol. 22:157-180.

5. Odoardi, F., et al. 2007. Instant effect of soluble antigen on effector $\mathrm{T}$ cells in peripheral immune organs during immunotherapy of autoimmune encephalomyelitis. Proc. Natl. Acad. Sci. U. S. A. 104:920-925

6. Matloubian, M., et al. 2004. Lymphocyte egress from thymus and peripheral lymphoid organs is dependent on S1P receptor 1. Nature. 427:355-360.

7. Tacke, M., Hanke, G., Hanke, T., and Hünig, T. 1997. CD28-mediated induction of proliferation in resting $\mathrm{T}$ cells in vitro and in vivo without engagement of the $T$ cell receptor: evidence for functionally distinct forms of CD28. Eur. J. Immunol. 27:239-247.

8. Lin, C.H., and Hünig, T. 2003. Efficient expansion of regulatory $\mathrm{T}$ cells in vitro and in vivo with a CD28 superagonist. Eur. J. Immunol. 33:626-638.

9. von Boehmer, H. 2005. Mechanisms of suppression by suppressor T cells. Nat. Immunol. 6:338-344.

10. Tischner, D., et al. 2006. Polyclonal expansion of regulatory $\mathrm{T}$ cells interferes with effector cell migration in a model of multiple sclerosis. Brain. 129:2635-2647.
11. Beyersdorf, N., et al. 2005. Selective targeting of regulatory T cells with $\mathrm{CD} 28$ superagonists allows effective therapy of experimental autoimmune encephalomyelitis. J. Exp. Med. 202:445-455.

12. Suntharalingam, G., et al. 2006. Cytokine storm in a phase 1 trial of the anti-CD28 monoclonal antibody TGN1412. N. Engl. J. Med. 355:1018-1028.

13. Stebbings, R., et al. 2007. "Cytokine storm" in the phase I trial of monoclonal antibody TGN1412: better understanding the causes to improve preclinical testing of immunotherapeutics. J. Immunol. 179:3325-3331.

14. O’Sullivan, N.L., Skandera, C.A., and Montgomery, P.C. 2001. Lymphocyte lineages at mucosal effector sites: rat salivary glands. J. Immunol. 166:5522-5529.

15. van den Brandt, J., et al. 2007. Enhanced glucocorticoid receptor signalling in $\mathrm{T}$ cells impacts thymocyte apoptosis and adaptive immune responses. Am. J. Pathol. 170:1-13.

16. Flügel, A., Willem, M., Berkowicz, T., and Wekerle, H. 1999. Gene transfer into CD4+ T lymphocytes: green fluorescent protein-engineered, encephalitogenic $T$ cells illuminate brain autoimmune responses. Nat. Med. 5:843-847.

17. Samstag, Y., Eibert, S.M., Klemke, M., and Wabnitz, G.H. 2003. Actin cytoskeletal dynamics in T lymphocyte activation and migration. J. Leukoc. Biol. 73:30-48.

18. Dennehy, K.M., et al. 2003. Mitogenic signals through CD28 activate the protein kinase CthetaNF-kappaB pathway in primary peripheral $\mathrm{T}$ cells. Int. Immunol. 15:655-663.

19. Geiger, B., Bershadsky, A., Pankov, R., and Yamada, K.M. 2001. Transmembrane crosstalk between the extracellular matrix - cytoskeleton crosstalk. Nat.
Rev. Mol. Cell Biol. 2:793-805.

20. Rainer, T.H. 2002. L-selectin in health and disease. Resuscitation. 52:127-141.

21. Cyster, J.G. 2005. Chemokines, sphingosine-1phosphate, and cell migration in secondary lymphoid organs. Annu. Rev. Immunol. 23:127-159.

22. Shiow, L.R., et al. 2006. CD69 acts downstream of interferon-alpha/beta to inhibit S1P1 and lymphocyte egress from lymphoid organs. Nature. 440:540-544

23. Brinkmann, V., et al. 2002. The immune modulator FTY720 targets sphingosine 1-phosphate receptors. J. Biol. Chem. 277:21453-21457.

24. Blum, K.S., and Pabst, R. 2007. Lymphocyte numbers and subsets in the human blood. Do they mirror the situation in all organs? Immunol. Lett. 108:45-51.

25. Fontoura, P., Steinman, L., and Miller, A. 2006. Emerging therapeutic targets in multiple sclerosis. Curr. Opin. Neurol. 19:260-266.

26. Reichardt, H.M., et al. 2001. Repression of inflammatory responses in the absence of DNA binding by the glucocorticoid receptor. EMBOJ. 20:7168-7173.

27. Dennehy, K.M., et al. 2007. Mitogenic CD28 signals require the exchange factor Vav1 to enhance TCR signaling at the SLP-76-Vav-Itk signalosome. J. Immunol. 178:1363-1371.

28. van den Brandt, J., Kwon, S.H., Hünig, T., McPherson, K.G., and Reichardt, H.M. 2005. Sustained pre-TCR expression in Notch1IC-transgenic rats impairs T cell maturation and selection. J. Immunol. 174:7845-7852.

29. van den Brandt, J., et al. 2004. Inhibition of Notch signaling biases rat thymocyte development towards the NK cell lineage. Eur. J. Immunol. 34:1405-1413. 